\title{
HACIENDO Y DESHACIENDO BALDÍOS: DINÁMICAS DE VALOR Y CONFLICTOS ENERGÉTICOS EN LA CATALUÑA SUR
}

\section{MAKING AND UNMAKING WASTELANDS: VALUE DYNAMICS AND ENERGY CONFLICTS IN SOUTHERN CATALONIA}

Jaume franquesa

Universidad de Buffalo

\section{Resumen}

En el Estado español, el desarrollo eólico ha seguido un modelo centralizado, concentrado en territorios rurales y de carácter extractivista. Esta última característica se hace patente cuando observamos que la puesta en valor del recurso viento ha supuesto la construcción de los territorios de donde tal recurso es extraído como lo que llamo "baldíos", es decir, su definición como carentes de valor. Este artículo examina la compleja dialéctica entre desarrollo eólico y dinámicas de valor a partir de un estudio de caso situado en la Cataluña Sur, una región que concentra una enorme variedad de infraestructuras energéticas. Mi descripción, basada en un trabajo etnográfico de larga duración, explora los mecanismos a través de los cuales la actividad de los promotores eólicos contribuye a abaratar material y discursivamente la región. Asimismo, argumento que la oposición que históricamente ha emergido en la zona en contra del desarrollo eólico debe ser comprendida como una reacción contra estas prácticas. Esta resistencia, que tiende a articularse como una demanda de dignidad, persigue afirmar y preservar el valor de las estrategias reproductivas locales, orientándose a reproducir las condiciones objetivas y subjetivas que hacen tales estrategias posibles.

Palabras clave: energía eólica, extractivismo, conflictos distributivos, valor, abaratamiento, periferalización. 


\begin{abstract}
In Spain, wind energy development has followed a centralized, extractivist model, with wind farms concentrated in peripheralized and impoverished rural territories. The ability of developers to extract value and electricity from these areas rests upon the latter's economic, ecological and cultural devaluation, that is to say, on its discursive and material construction as wastelands. This paper examines the dialectical relationship between devaluation and wind energy development through a specific case study from Southern Catalonia, a region that concentrates a large array of energy-related infrastructure. Basing my description on long-term ethnographic fieldwork, I explore the mechanisms through which wind developers aimed to materially and discursively devalue the region, and more specifically its land and the livelihoods it supports. Finally, I argue that opposition to wind energy development emerges, fundamentally, as a reaction against these devaluation practices. A struggle - which takes place through and in the idiom and dignity - that aims to assert and preserve the value of local reproductive strategies and the objective and subjective conditions that make them possible
\end{abstract}

Keywords: wind energy, extractivism, distribution conflicts, value, cheapening, peripheralization.

"El abaratamiento [de la naturaleza] siempre posee dos caras. Una tiene que ver con el precio: reducir costos, directos e indirectos, al capital. La otra es ético-política: abaratar (...) en el sentido de tratar como no digno de respeto" (Moore, 2017: 600) ${ }^{1}$

En 2012, entrevisté a Eudald, ingeniero y miembro de la familia propietaria de una empresa constructora catalana a la que llamo Obrisa. A finales de los años noventa, Eudald lideró la expansión eólica de Obrisa, que se concretaría en el registro de siete proyectos de parques eólicos en diversas comarcas catalanas. Tres de estos proyectos, y a la postre los únicos que a día de hoy han visto la luz, se encontraban en los alrededores de La Fatarella, un pueblo de unos mil habitantes de la comarca de la Terra Alta, en el sur de Cataluña. Pero cuando le entrevisté Eudald ya no era el dueño de esos parques, ya que entre 2010 y 2011 los vendió a la multinacional eléctrica EDP (Energias de Portugal) por un montante cercano a los 28 millones de euros. Esta cifra es especialmente elevada si se tiene en cuenta que en el momento de la venta Obrisa ni tan siquiera había empezado a

1. La traducción de las citas textuales cuya referencia aparece en el apartado bibliográfico en una lengua distinta al castellano es mía. También he traducido del catalán al castellano las citas orales procedentes del trabajo de campo. 
construir los parques. Como suelen decir los lugareños, Obrisa "sólo vendió papel": los acuerdos con los municipios, los permisos y licencias de las distintas administraciones involucradas, los derechos para construir una línea eléctrica para conectar los parques a la red de media tensión, y una proporción considerable de contratos con los propietarios de las parcelas de tierra afectadas por los parques. A partir de la venta, EDP se encargó, entre 2012 y 2013, de la construcción y puesta en operación de los parques, que siguen en funcionamiento.

Durante la entrevista, Eudald me dijo que lamentaba haber tenido que vender los parques, una decisión que me presentó como ajena a sus deseos, motivada por las dificultades financieras que su empresa experimentó a partir de la crisis de 2008. Pero más allá de los lamentos, Eudald prefirió poner el énfasis en el impacto positivo, tanto a nivel ambiental como social, de su actividad. Destacó que la energía eólica era clave para combatir el cambio climático, y que además contribuía a la soberanía energética del país. También subrayó los beneficios que su actividad reportaba a las áreas rurales donde se llevaba a cabo:

"Allí donde voy me encuentro pobreza. Los ayuntamientos de los lugares ventosos, que en general son lugares remotos, son lugares donde ha habido un éxodo (...) del campo a la ciudad. Son pueblos cuyo presupuesto municipal no permite ni mantener el pueblo con la mínima decencia. (...) Y lograban [con la actividad eólica], de alguna manera, ganar. La gente mayor veía que los jóvenes volvían a pasar las vacaciones y se podían hacer unas fiestas mayores decentes, una piscina para los nietos... (...) Yo he visto llorar a señoras mayores, que su pensión no les llegaba, y de repente les cae un generador y un alquiler. (...) La tierra, aquí en Cataluña, es ya bastante mala (...) y de repente en un rincón del campo te plantan un molino (...) pues esto es un arreglo para esa familia que no sabía como afrontar la vejez, de algo [la tierra] de la que no sacaba nada, sólo gastos”.

Conviene fijarse en que, para destacar el beneficio de su actividad para los habitantes de la Terra Alta, Eudald necesita presentar la región como un baldío: un lugar sin valor, hecho de pobreza y aislamiento que sólo puede ser salvado, redimido, gracias a empresarios ilustrados como él que sean capaces de ver más allá de la miseria para realizar así un valor latente e invisible a los ojos del común. Conviene también observar que el hecho de que la población local padezca necesidades es útil para los objetivos de Eudald: las áreas pobres favorecen la tarea a los promotores eólicos, ya que les facilitan las negociaciones con propietarios y ayuntamientos, permitiéndoles pagar menos. Ello quedó claro cuando le pregunté por qué no había sido capaz de llevar adelante los parques eólicos que tenía bajo registro en otras partes de Cataluña. Al responderme, dio la vuelta a su argumento anterior: 
La gente, sobre todo en lugares ventosos, en los lugares más despoblados del país, que ha acabado deviniendo el jardín de la gente de Barcelona... [ahí] la gente liga los perros con longanizas, son ricos, Cataluña es un país rico. Vas al Empordà y no quieren nada. (...) La democracia la hemos pervertido un poco y aquí parece democrático dar voz a un payés que de electricidad no sabe nada.

Según Eudald, pues, existe una relación inversa entre el valor del lugar y el grado de oposición local al desarrollo de la energía eólica. No obstante, este argumento tiene puntos débiles. Para empezar, aunque no faltaron quienes vieron el desarrollo eólico con buenos ojos, en la Terra Alta el desarrollo eólico nunca suscitó apoyos amplios ni entusiastas. Más bien al contrario: no sólo emergieron en su contra grupos bien organizados, sino que también fue objeto de lo que siguiendo a Scott (1985) podríamos llamar "formas de resistencia cotidiana”. Pero hay más: la descripción del bajo valor de la Terra Alta como algo obvio, algo que Eudald simplemente se encontró, debe ser problematizada ya que tiende a ocultar la variedad de prácticas empleadas por Obrisa para devaluar la región material y discursivamente. Como mostraré, estas prácticas fueron claves para sus objetivos, puesto que le permitieron desembarazarse de las formas de resistencia que emergieron contra sus proyectos.

Este artículo pretende descifrar las complejas relaciones entre devaluación (o abaratamiento) y desarrollo eólico a partir del análisis del caso de la Cataluña Sur, y más concretamente del desarrollo de los tres parques eólicos de La Fatarella ${ }^{2}$. La descripción del caso se basa en un trabajo de campo etnográfico llevado a cabo durante once meses discontinuos entre 2010 y 2014, seguidos de posteriores visitas más cortas. Como parte del trabajo de campo, realicé entrevistas con promotores eólicos, cargos electos (alcaldes y concejales de diversos pueblos), personal de la administración (comarcal, provincial y autonómica), propietarios afectados por los parques, y miembros de grupos ecologistas y de diversas plataformas activistas locales, incluidas las "anti-eólicas". Gracias a la generosidad de distintos acaldes de La Fatarella, que me dieron acceso al archivo municipal, también pude realizar un minucioso análisis documental del proceso de tramitación de los parques eólicos. El proceso de observación participante incluyó la visita a varias centrales eléctricas de la región, así como la participación en asambleas y manifestaciones, pero se centró fundamentalmente en comprender los modos de vida de la población local de La Fatarella y sus alrededores, acompañándola en sus tareas agrarias y participando en la vida social habitual y festiva del lugar (Franquesa, 2018).

2. El desarrollo eólico en la Cataluña meridional ha sido objeto de una atención académica considerable, tanto por cantidad como por calidad, dentro de la cual destacan trabajos como Zografos y Martínez Alier (2009), Ariza-Montobbio (2013) y Saladié (2018). 
El análisis que ofreceré en este artículo muestra que la capacidad de los promotores eólicos para conseguir beneficios reposa sobre la devaluación económica, ecológica y cultural de los territorios donde se ubican los parques eólicos. Argumento que ello es reflejo del carácter extractivista que ha tomado el desarrollo eólico en el Estado español. El término extractivismo ha sido objeto de intenso debate en los últimos años ${ }^{3}$. En lo fundamental, identifica un tipo de actividad económica caracterizada por: 1) el control monopolístico de un recurso (en este caso, el viento); 2) la transferencia a otros lugares, generalmente más ricos y centrales, de los bienes (en este caso, la electricidad) y beneficios obtenidos; y 3) lo que Anna Tsing (2015) denomina un proceso de alienación, por el cual la valorización del recurso a extraer va acompañada de la definición como carente de valor del contexto en el que inicialmente se encontraba incrustado dicho recurso. En la Cataluña Sur, la valorización del viento ha implicado sujetar la tierra y los modos de vida locales a procesos de desvalorización moral y devaluación económica. Ello ha provocado la reacción de la población local, cuya resistencia al desarrollo eólico debe ser entendida, primera y fundamentalmente, como parte de una lucha para afirmar y conservar el valor del lugar y de sus gentes que tiende a expresarse como una demanda de dignidad.

\section{LOS COLORES DEL VIENTO}

Durante años la reflexión alrededor de las energías renovables estuvo dominada por un supuesto, a saber: que, dado su carácter descentralizado, el uso de fuentes renovables se traduciría en sistemas eléctricos distribuidos y con altas dosis de participación y control local (Oceransky, 2010). Sin embargo, el progresivo desarrollo de la energía eólica ha puesto en evidencia la debilidad de este argumento: en determinados casos, el desarrollo eólico conlleva la descentralización del sistema eléctrico; en otros, reproduce su carácter centralizado. Hvelplund (2014) se refiere a estas dos modalidades como "eólica verde" y "eólica negra". La eólica verde se caracteriza por la participación local en el planeamiento y la propiedad de los generadores, así como por la alta dispersión de la generación y por reducir la distancia entre consumidores y productores. La eólica negra tiende a prevalecer en contextos institucionales que privilegian los beneficios económicos por encima de los ambientales (Szarka, 2007). En contraste con la primera, se caracteriza por un planeamiento centralizado desde instancias de poder, por el tamaño relativamente grande y el carácter concentrado de las unidades de generación, y por la segregación entre consumidores y productores, con una estructura de la propiedad de los aerogeneradores en manos de grandes empresas cuya relación con el entorno local es escasa y cuyo modelo de negocio reposa sobre la producción de electricidad a granel para una demanda que se asume como homogénea y creciente.

3. Véase Márquez Porras (2019) para una revisión reciente de esta literatura, y Siamanta y Dunlap (2019) para su aplicación a la energía eólica. Para un análisis teórico reciente de la relación entre recursos naturales, valor y extracción, véase Franquesa (2019a). 
Según Hvelplund (2014) el principal problema de la eólica negra es que al promover la centralización del sistema eléctrico tiende a fomentar la oposición local, que es mucho menos probable en el caso de la eólica verde. Los estudios etnográficos disponibles apoyan esta conclusión. En este respecto, el caso modelo lo encontramos en el Istmo de Tehuantepec, en México, donde varios investigadores (Ávila-Calero, 2017; Boyer y Howe, 2019; Dunlap, 2019) han mostrado que la resistencia local viene en gran parte motivada por la escala de los proyectos eólicos, por el hecho de estar en manos de grandes empresas extranjeras, y por el grado de autoritarismo y violencia que ha marcado su proceso de planificación e instalación. De manera similar, Argenti y Knight (2015) muestran que, en un contexto marcado por la crisis de la deuda, la oposición a varios proyectos de energía renovable en Grecia se alimenta de la memoria de la dominación semi-colonial del país y por el temor ciudadano a que se repitan procesos de desposesión. La importancia de estos hallazgos debe ser subrayada. En este artículo, sin embargo, defenderé que podemos conseguir una comprensión más profunda de la oposición local a la eólica negra si concedemos prioridad analítica a los procesos de devaluación que la caracterizan, puesto que tal enfoque permite examinar las múltiples escalas en las que este modelo de desarrollo energético produce y reproduce relaciones desiguales.

Basando su análisis en la Cataluña Sur, Zografos y Martínez Alier proponen que la oposición local a este desarrollo debe entenderse como expresión de un conflicto de distribución ecológica, que definen como "lucha[s] para revertir tanto las inequidades de poder existentes o emergentes como la distribución desigual de los costos y beneficios resultantes de la modificación del ecosistema o el paisaje" (2009: 179). Como sugiere la cita, tal desigualdad ecológica suele tener también un componente económico que, en el caso eólico, se pone de manifiesto al observar la tendencia de los parques eólicos a estar situados en zonas con alta prevalencia de desempleo y problemas de salud (Nadaï y van der Horst, 2010). Pero tal y como plantea Arturo Escobar, los conflictos de distribución poseen una tercera dimensión que a menudo se pasa por alto - la cultural: "si la producción bajo una distribución desigual niega los procesos ecológicos, también niega los procesos culturales que se encuentran en la base de la valorización y la relación de la gente con el mundo natural" (2005: 127). Así, pues, el análisis de los conflictos de distribución debe esforzarse en mostrar "los efectos de hacer ciertos valores y prácticas culturales inconsecuentes a través de efectos de dominancia y hegemonía" (2005: 130).

En la Cataluña Sur, el valor de la tierra y de las prácticas locales es el locus clave de los conflictos alrededor de la energía eólica. Esta centralidad emana de lo que Jason Moore (2017) llama procesos de abaratamiento, un abaratamiento que, como se puede observar en la cita que sirve de epígrafe al artículo, es simultáneamente económico y moral o, si se quiere, cultural. Tales procesos de abaratamiento son funcionales para los promotores ya 
que, de un lado, les ayudan a esquivar y/o derrotar las resistencias locales y, del otro lado, les permiten pagar menos por el acceso al recurso viento.

Para refinar nuestra comprensión del aspecto dual de los procesos de abaratamiento, propongo que nos fijemos en la obra teórica que el geógrafo Vinay Gidwani ha desarrollado alrededor del concepto de waste, que traduciré como baldío. En sus trabajos iniciales, Gidwani (1992) analiza el modo como la administración colonial británica en la India utilizó la categoría legal de waste, que identificaba ciertas parcelas de tierra como improductivas, para justificar procesos de desposesión. Más importante, esta categoría rápidamente se proyectó más allá de la tierra para abarcar aquellas actividades humanas que no generaban un valor mercantilizable. En sus trabajos más recientes, Gidwani (2012) ha abordado la noción de waste como una categoría analítica más general, capaz de iluminar la lógica del capitalismo en tanto que orden económico, ecológico y moral. La riqueza de significados del término waste - aquello irracional, estancado, ineficaz, desordenado - encuentra su coherencia en contraste con la definición capitalista del valor. Así, Gidwani argumenta que el capital encuentra su vitalidad y justificación moral en los proyectos para disciplinar, conquistar y erradicar los baldíos: al definir ciertas actividades, personas y lugares como baldíos, el capital automáticamente los constituye como "enemigos a los que hay que derrotar" (Gidwani, 2012: 277).

La categoría de baldío, en el sentido amplio aquí propuesto, posee siempre una doble dimensión. La primera es negativa: lo que es innecesario o sobrante, descartable; la segunda, positiva: lo que puede ser rescatado, un potencial desaprovechado. Estos dos aspectos se articulan dialécticamente: es porque ciertos territorios, actividades y personas son construidos como yermos y baldíos - residuales, marginales, inútiles - que el capital puede justificar la necesidad de intervenir para hacerlos productivos. Gidwani concluye afirmando que esta dialéctica divide el mundo entre dos tipos de personas y de espacios. Por un lado, personas el trabajo de las cuales es valorado y recompensado y la vida de las cuales es tratada como digna de ser cultivada; por el otro, personas percibidas como irrelevantes para el funcionamiento del mercado, cuya vida es abaratada, usada y fácilmente descartada. Como mostraré en la siguiente sección, esta dialéctica ha sido una constante histórica del proceso de desarrollo energético en la Cataluña Sur.

\section{LA CATALUÑA SUR COMO PERIFERIA EXTRACTIVA}

Como han señalado diversos autores (por ejemplo: Szarka, 2007; Barcia Magaz y Romero, 2014), el desarrollo eólico en el Estado español se ajusta a la caracterización propuesta de la eólica negra. Una gran parte de la propiedad de los parques eólicos está en manos de empresas eléctricas oligopolísticas y cada vez más de fondos de inversión, a lo que hay que sumar algunas grandes y medianas empresas del sector de la construcción. Más allá de las diferencias por comunidades autónomas, el proceso administrativo para instalar 
parques eólicos se ha caracterizado por su opacidad burocrática - lo cual ha sido un caldo de cultivo idóneo para fomentar las sospechas, a veces bien fundadas, de corrupción y clientelismo - mientras que los mecanismos de participación ciudadana han sido débiles y escasos, cuando no directamente inexistentes. Geográficamente, la estructura de generación es relativamente concentrada, con parques eólicos moderadamente grandes (entre 30 y $50 \mathrm{Mwh}$ ) aglomerados en territorios rurales de interior periféricos (y periferalizados), a menudo despoblados y empobrecidos. Una bajísima proporción de los 23 Gwh de la capacidad instalada total en el Estado español se sitúa cerca de la costa o de las áreas urbanas, los dos tipos de territorios que concentran más población y riqueza. Es decir, los parques eólicos se concentran en aquellas zonas geográficas que cumplen las funciones de extracción y sumidero (Carpintero, 2015). Así, pues, nos encontramos con que en el Estado español hay una fuerte correlación entre el grado de periferalidad y la existencia de parques eólicos, mientras que la correlación con la calidad y la cantidad de viento sólo es un predictor válido en el interior de las zonas periféricas (Franquesa, 2018).

La Cataluña Sur es una de estas zonas. Con el término Cataluña Sur me refiero a las cinco comarcas más meridionales de Cataluña (Baix Ebre, Montsià, Priorat, Rivere d'Ebre y Terra Alta), cruzadas por el río Ebro y cuya población asciende a unos 200.000 habitantes. Aunque como tal la región carece de entidad administrativa ${ }^{4}$, existe en la zona un fuerte sentimiento de identidad compartida, vehiculada a través de marcadores como la variedad dialectal del catalán que la distinguen del resto del Principado. La zona posee una baja densidad poblacional (su única ciudad destacable es Tortosa, con unos 30.000 habitantes), su tejido industrial es débil, y la renta familiar es un $20 \%$ inferior a la media catalana. El carácter rural de la zona es especialmente acusado en sus tres comarcas septentrionales (Priorat, Ribera d'Ebre y Terra Alta), marcadas desde el siglo XVIII por una agricultura familiar comercial basada en la producción de cultivos mediterráneos y sus derivados (en especial, vino y aceite de oliva). En la actualidad, si bien la mayor parte de unidades domésticas poseen tierra agrícola y la cultivan, son muchas menos las que derivan su ingreso principal de tal actividad, y la mayoría combina distintas fuentes de ingreso (pensiones, rentas agrícolas, salarios, pequeños negocios). A pesar de ello, los habitantes de la zona se definen en su gran mayoría como "payeses" (pagesos), un término que con el tiempo y la caída de los ingresos agrícolas ha ido cada vez más definiendo una cierta identidad local ligada al campo, identificando no sólo a aquellos que viven de la tierra sino a todos aquellos que viven y quieren vivir en la tierra y a través de ella.

\footnotetext{
4. Cuatro de estas comarcas (el Priorat es la excepción) conforman el "ámbito funcional territorial" Terres de l'Ebre, una división establecida en 1995 y con ciertas competencias en términos de administración territorial.
} 
Especialmente importante para este artículo, la Cataluña Sur (y en especial su mitad septentrional) concentra una inmensa y variada infraestructura energética. El origen de esta concentración hay que buscarlo en las últimas décadas del régimen franquista. Así, mientras la región sufría los efectos del desarrollismo franquista, especialmente un acusado éxodo poblacional, adquiría una nueva especialización funcional como receptora de la infraestructura energética que aquel desarrollo requería. La llegada de instalaciones energéticas se inició en los años sesenta con la construcción de la presa hidroeléctrica de Riba-Roja para continuar, ya en los años setenta, con los proyectos, finalmente descartados, de ubicar otras dos presas río abajo (en Xerta y Garcia) y, de manera crucial, con la llegada de diversos proyectos nucleares que culminarían, ya en los años ochenta, con la instalación de cuatro reactores nucleares (Vandellòs I y II, y Ascó I y II), convirtiendo la región en la más nuclearizada del Estado (Garcia, 1997). La oposición local a estos proyectos energéticos, sobre todo a las nucleares, fue notable, en especial durante la Transición, funcionando en la región como una de las caras más potentes de la lucha contra la Dictadura y su herencia (Fernández 1999).

A finales del siglo XX se inicia una segunda fase en el proceso de especialización funcional de la región. A finales de los años noventa se anuncian el Plan Hidrológico Nacional (PHN), que incluía el trasvase del Ebro, y el proyecto de Enron de construir la mayor planta de ciclo combinado de Europa en la región, a los que hay que añadir, como veremos, un gran número de proyectos eólicos. Unos años más tarde a todo ello se sumarán, junto con nuevos planes más o menos encubiertos de trasvase, el proyecto Castor de construcción de un depósito submarino de gas natural (que inicialmente debía situarse frente a Alcanar) y los planes para ubicar en Ascó el Almacén Temporal Centralizado de residuos nucleares, localmente llamado "cementerio nuclear". Todos estos proyectos suscitaron, sin excepción, una gran oposición popular que jugó un papel clave a la hora de forzar la retirada (temporal o permanente) de muchos de ellos.

El momento más álgido de esta oposición se dio a principios de este siglo, cuando emergieron una serie de plataformas locales que vehicularon el descontento popular en la región. Aunque formalmente independientes, todas estas plataformas (incluidas la Plataforma del Priorat y la Plataforma de la Terra Alta, dedicadas al tema eólico) trabaron fuertes alianzas basadas en un diagnóstico compartido. En una conversación que tuve durante mi trabajo de campo, Teresa, una de las portavoces de la Plataforma en Defensa de l'Ebre (PDE), lo expresó así: "Somos luchas hermanas, luchamos contra un mismo modelo de desarrollo en el que somos periféricos: despensa de agua y energía, y vertedero, nuclear o no, de toda Cataluña”. La frase de Teresa ilustra perfectamente que, a ojos de las plataformas y de una mayoría de ciudadanos de la zona, lo que estaba ocurriendo era un conflicto de distribución. Los catalanes del sur no querían ser un vertedero ni un lugar de extracción para el metabolismo sobredimensionado de la España (y la Cataluña) de 
la época del boom inmobiliario, con su alta demanda de energía y materiales. Más allá, los activistas denunciaban lo que entendían que era una clara correspondencia entre, de un lado, una distribución desigual en términos económicos y ecológicos y, del otro, una falta de reconocimiento político y de respeto cultural. Esta correspondencia puede ser observada en la siguiente cita de Manolo Tomàs, el carismático líder de la PDE:

Nuestra tierra representa el sur de Cataluña, con todos los significados de la palabra sur. (...) La voluntad que expresamos es la voluntad de ser y de existir. Nosotros lo llamamos dignidad ebrenca. También somos catalanes y el territorio en el que vivimos es el patrimonio de las generaciones futuras. Lo que cuestionamos es, en el fondo, el modelo territorial. La concentración de recursos e infraestructuras en las grandes ciudades condena a la pobreza y a la despoblación a las áreas periféricas, y esto se tiene que acabar (Tomàs, 2002: 8-9).

La oposición al desarrollo eólico debe situarse dentro de este contexto general de lucha, es decir, como parte de una resistencia más amplia contra los procesos de extracción y periferalización que afectaban a una región que, como los activistas solían repetir, ya generaba más electricidad de la que le correspondía. Como se ha mencionado anteriormente, los proyectos eólicos llegaron a la Cataluña Sur a finales de los años noventa y encontraron respaldo institucional en el Mapa Eólico, un documento aprobado por la Generalitat en 1999 que definía gran parte de la región como idónea para el desarrollo eólico. Entre los alcaldes de los municipios receptores de estos proyectos, la reacción fue variada e incluso contradictoria, fluctuando entre dos polos: de un lado, el entusiasmo total de aquellos que celebraban la energía eólica como una oportunidad única de desarrollo económico; del otro, la cautela de aquellos que, dada la ausencia de directrices de planificación, la falta de información sobre este tipo de energía y el desequilibrio entre el poder económico de promotores y municipios, temían que el proceso se les pudiera escapar de las manos, dando lugar, entre otras consecuencias indeseadas, a una competición a la baja entre municipios que sólo beneficiaría a las empresas. Por otra parte, la proliferación de proyectos eólicos y la falta de una planificación general que regulara su instalación provocó la creación de las plataformas del Priorat y la Terra Alta, que canalizaron el desconcierto y el enfado de muchos habitantes de la zona. Ambas plataformas pusieron énfasis en subrayar que no estaban en contra del desarrollo eólico sino contra lo que denominaron "masificación eólica", reivindicando que se redujera el número de proyectos y que se implementaran mecanismos para consensuar su ubicación con la población local. Más allá, aprovecharon el concepto de Nueva Cultura del Agua desarrollado por la PDE y sus aliados para esbozar lo que llamaron una Nueva Cultura de la Energía, que proponía que el crecimiento de la oferta y la demanda dejara de ser el criterio que guiaba la política energética, reivindicando en su lugar un nuevo modelo 
de sistema eléctrico cuyos ejes centrales serían la conservación energética, la producción distribuida y el cierre de las nucleares.

Puesto que el foco central de interés de este artículo es el análisis y descripción de las formas de resistencia cotidiana contra el desarrollo eólico, no dispongo del espacio necesario para entrar en la descripción detallada de las actividades de las plataformas del Priorat y la Terra Alta. No obstante, sí vale la pena remarcar que ambas entidades, y con ellas sus respectivas comarcas, mantuvieron trayectorias divergentes. Casi desde su fundación, la Plataforma del Priorat fue capaz de congregar a su alrededor un amplio apoyo por parte de grupos influyentes de la sociedad civil local, encabezados por el potente sector vitivinícola y en especial por las bodegas privadas que desde mediados de los años noventa estaban experimentando un notable crecimiento. Gracias a este apoyo y a la habilidad organizativa de sus líderes para generar complicidades políticas, la Plataforma del Priorat fue capaz, ya desde los primeros años de este siglo, de generar un gran consenso en la comarca, superando así las voces contradictorias de sus alcaldes. Esta plataforma supo articular su reivindicación de frenar el crecimiento eólico como una demanda en positivo, es decir, como una defensa del paisaje local, entendido a la vez como recurso económico endógeno distintivo y como valor patrimonial innegociable (Saladié, 2018). Al enfocar la cuestión en estos términos, la Plataforma del Priorat reforzó en la mente de promotores y población local la asociación entre desarrollo eólico y devaluación. De hecho, el éxito de la Plataforma del Priorat tuvo un gran impacto sobre la vecina Terra Alta, la comarca que a partir del año 2002 pasaría a concentrar casi en exclusiva el interés de los promotores eólicos. Incapaz de parar el desarrollo eólico, a partir de 2004 la Plataforma de la Terra Alta, cada vez más aislada y sufriendo divisiones internas, fue perdiendo fuelle y, aunque más adelante (en especial entre 2008 y 2012) volvería a ganar fuerza, nunca fue capaz de generar el tipo de consenso que se dio en el Priorat.

\section{LA PRODUCCIÓN DE BALDÍOS}

A medida que el desarrollo eólico avanzaba en la Terra Alta y que su plataforma iba perdiendo fuerza, empezaron a coger protagonismo formas más subterráneas de resistencia. Entre estas formas de resistencia cotidiana podemos incluir desde los rumores más o menos malintencionados - por ejemplo, sobre los supuestos favores que los promotores pagaban a los alcaldes y sus familiares - hasta pequeñas acciones de sabotaje - por ejemplo, bloquear con el tractor el acceso de los operarios eólicos a las fincas. Pero sin duda la forma de resistencia más importante fue el rechazo por parte de muchos propietarios de los acuerdos que la compañía les ofrecía para acceder a sus tierras. Como argumentaré en la siguiente sección, esta resistencia debe entenderse como una defensa contra los esfuerzos de las compañías eólicas para construir la Terra 
Alta como un baldío, es decir, como un lugar periférico, necesitado y sin posibilidades de desarrollo endógeno, cuyo escaso valor era consecuencia directa de la baja productividad de las prácticas locales. Esta sección se centra en estos esfuerzos, que ilustraré a través de dos de los mecanismos empleados por Obrisa: la expropiación forzosa y el fomento de la división social.

\subsection{Expropriaciones}

El interés de Obrisa por la Terra Alta arrancó en 1998, año en el cual empezó a negociar con el Ayuntamiento de La Fatarella. Después de tres años de conversaciones, las dos partes firmaron un convenio para la construcción de un parque eólico cuya finalización se preveía en 2007. El convenio estipulaba el valor de los contratos que el promotor debía pagar en concepto de arrendamiento anual por la instalación de cada aerogenerador (unos 6.000 euros), a la vez que obligaba al ayuntamiento a colaborar con la empresa y, en especial, a facilitarle sus negociaciones con los propietarios de tierras. El convenio también incluía una serie de cláusulas que emplazaban a la compañía a comprometerse a contratar mano de obra local, respetar el entorno construido (en especial la arquitectura vernácula de piedra seca, muy querida y abundante en el entorno agrícola de la zona) y a invertir en la promoción turística de la villa, estudiándose incluso la posibilidad de crear un centro de visitantes dedicado a las energías renovables que quedaría en papel mojado. De hecho, esta última serie de cláusulas no iba acompañada de medidas de seguimiento y su cumplimiento fue bastante bajo. Poco después de firmar con La Fatarella, Obrisa firmó convenios casi idénticos con los municipios colindantes de Vilalba y Corbera, con la particularidad de que los parques eólicos correspondientes a estos dos pueblos, aunque sitos dentro de su término municipal, se encontraban a escasa distancia del núcleo habitado de La Fatarella y en terrenos cuya propiedad estaba mayoritariamente en manos de habitantes de esta localidad.

En 2003, Eudald empezó ya a preparar la ejecución de sus proyectos. Con este fin reclutó a un pequeño grupo de ingenieros para tirar adelante el diseño de los parques y las negociaciones con los propietarios. Al mismo tiempo solicitó, al igual que hicieron el resto de promotores eólicos de la comarca, un punto de evacuación a Red Eléctrica Española. Pero la respuesta del operador les generó un importante problema puesto que el punto de evacuación propuesto (concretamente, en la central hidroeléctrica de RibaRoja, más allá de los confines septentrionales de la comarca) era mucho más distante de lo que esperaban, hecho que complicaba sus gestiones a la vez que aumentaba la inversión necesaria. La Generalitat intervino para solucionar este problema, promoviendo la creación de un consorcio privado, al que llamaré Terraca, que agrupaba a las distintas empresas promotoras, siendo Eudald su director. La misión de Terraca era construir una línea eléctrica de unos cuarenta quilómetros que evacuaría a la red la electricidad de diez parques eólicos (424 Mwh, 183 generadores) de forma conjunta, con cada promotor 
haciéndose cargo del segmento que le correspondía. La magnitud del proyecto era considerable: sólo la parte de la línea correspondiente a los parques de Obrisa afectaba a más de cien propietarios.

Desde un inicio Obrisa experimentó enormes dificultades para llevar adelante la línea, ya que una mayoría de los propietarios afectados rechazó los contratos que la compañía les ofrecía y que consistían en un pago único a cambio de conceder el derecho de acceso a sus propiedades. La desconfianza hacia los promotores se extendió y las carreteras de la comarca pronto se llenaron de pintadas con un mensaje claro: ¡No firmes! Aunque muchos propietarios consideraban la cantidad ofrecida ridículamente baja, el rechazo generalizado a los contratos tenía mucho más que ver con el carácter privado de Terraca y con el hecho que los habitantes de la comarca no sentían como suyo un proyecto del que esperaban obtener escasos beneficios. Así nos lo cuenta Eugènia, trabajadora de una empresa de ingeniería especializada en valoraciones de suelo rústico, quien, de forma más o menos simultánea, fue contratada para valorar terrenos y ofrecer contratos tanto por Terraca (y después Obrisa) como por un proyecto de la Generalitat para instalar un sistema de riego agrícola para el conjunto de la comarca:

"Con el proyecto del riego yo hacía acuerdos y pagaba poquísimo. (...) Acuerdos con el riego, 99 por ciento; con los parques eólicos, haciendo muchos esfuerzos, pero muchos, y muchas historias y cosas, no sé si llegamos al 60 o al 50 por ciento. Pero haciendo muchos esfuerzos, muchos, y pagando mejor. (...) Y esto es porque el riego era para ellos, lo otro es para gente de Barcelona que vienen a robarnos el dinero, que gracias a mí hacen un negocio."

Ante la resistencia de los propietarios, Terraca contraatacó con una doble estrategia. Por un lado, contrató a un lobby para cortejar a los alcaldes locales reticentes y emprender una campaña de prensa y relaciones públicas para mejorar la imagen del desarrollo eólico. Por el otro, comisionó un equipo de economistas para llevar a cabo un estudio para evaluar el futuro impacto de los parques eólicos sobre la economía comarcal. El estudio, concluido en 2006, presentaba la comarca como un caso perdido, es decir, como un baldío. La agricultura local, explicaba, era recesiva y estaba estancada, sin apreciarse posibilidades de que se pudiera transformar con criterios "modernos y racionales"; por su parte, el tejido industrial y de servicios (desde pequeñas industrias hasta cooperativas agrarias, bodegas y establecimientos turísticos familiares) era presentado como débil e incapaz de absorber la demanda de empleo de la población local. El estudio, pues, concluía que la única solución que le quedaba a la comarca era atraer inversión externa: los parques eólicos eran esa inversión, una oportunidad que no se podía dejar escapar. No obstante, al entrar en los detalles, el estudio tenía dificultades para probar su argumento, pues admitía que los parques crearían muy pocos puestos de trabajo y calculaba que su impacto positivo sobre la renta familiar comarcal sería tan solo del uno por ciento. 
Todo parece indicar que el estudio tuvo escaso impacto sobre una población local acostumbrada a este tipo de documentos, ya que cada proyecto energético parece ir acompañado de un estudio donde se deplora la situación de la región mientras se cantan las virtudes del proyecto en cuestión. Pero éste no era el objetivo de Terraca. Su objetivo era que el estudio apoyara la declaración de utilidad pública de la línea eléctrica por parte de la Generalitat. Gracias a esta declaración, la administración podía expropiar los terrenos necesarios a beneficio de Obrisa. Con esta amenaza en mano, Terraca envió una segunda oferta, por lo general inferior, a los propietarios recalcitrantes: si no la aceptaban serían expropiados. La mayoría aceptó. Más adelante, Obrisa empezaría a negociar con los propietarios afectados por los parques eólicos. Encontrándose nuevamente con un amplio rechazo, la compañía repetiría su estrategia, obteniendo la declaración de utilidad pública para los tres parques eólicos.

La posibilidad de llevar a cabo procesos de expropiación forzosa fue, sin ninguna duda, el principal mecanismo por el que la empresa pudo sobreponerse a la resistencia que se le ofrecía. No obstante, esta estrategia también intensificó la hostilidad entre la población local.

\subsection{Hacerse monte}

Al quejarse sobre las maniobras de Obrisa, los habitantes de La Fatarella suelen usar una expresión recurrente: "Se han hecho los dueños" (s'han fet los amos). Éste es literalmente el caso con las expropiaciones, pero la expresión tiene un sentido más amplio, refiriéndose a la capacidad de la empresa para controlar y administrar el entorno físico y social del pueblo. Si las expropiaciones dejaron claro que Obrisa trataba la tierra como un baldío, varias prácticas posteriores reforzarían esta idea en la mente de los habitantes de la Fatarella: la entrada en propiedades privadas, la imposibilidad de negociar los términos de los contratos, la amenaza de mover generadores a parcelas colindantes, la sospecha constante de que se ofrecían favores clientelares, y la falta de cuidado con la arquitectura vernácula. Todo ello contribuyó a erosionar el sentimiento entre la población local de control sobre su propio entorno. La entrada no autorizada a parcelas por parte de partidas de obreros trabajando en parcelas vecinas resultaba especialmente hiriente, no tanto por el hecho en sí como por la falta de respeto que sugería, tal y como la ilustra la respuesta que un capataz dio ante la queja de una propietaria: "Esto no es propiedad privada, señora. Esto es el monte". El comentario es especialmente insultante si tenemos en cuenta que en La Fatarella trabajar el campo, hacer de payés, es en buena medida entendido como una tarea constante consistente en mantener el monte, la garriga, a raya. La traducción más ajustada de garriga es "carrascal", pero en su uso más amplio debe comprenderse como equivalente a "monte", identificando aquella naturaleza que queda fuera del cuidado humano. Así, mientras trabajar el campo es concebido como una actividad orientada a dotar de propósito y dirección al entorno natural, el monte es 
la metáfora por excelencia para referirse a aquello que está desorganizado, descuidado. La queja de que Obrisa había devenido el nuevo dueño también hace referencia a la capacidad de la compañía de controlar la vida social y política de la villa. Ello se hizo muy evidente durante y después de las elecciones municipales de 2007, en las que tres partidos obtuvieron ediles sin que ninguno consiguiera mayoría absoluta ni se llegara a acuerdos estables de gobierno. Habida cuenta del malestar general que las expropiaciones habían generado, los tres partidos planteaban modificar el proceso de desarrollo eólico, y para ello presentaron mociones diversas y a menudo contradictorias que incluían, entre otras, desde la retirada unilateral del convenio por parte del municipio hasta la reubicación de los parques. Vista la incapacidad de llegar a acuerdos políticos, se empezó a generar un cierto consenso para celebrar una consulta popular y dejar la decisión en manos de la ciudadanía. Pero Obrisa se cerró en banda a esta posibilidad. Consultada por el Ayuntamiento, la Diputación emitió un informe en el que desaconsejaba tal referéndum, pues advertía que la posible retirada del Ayuntamiento respecto a sus compromisos para con el promotor abrían la posibilidad de un litigio que podía llevar al primero a la bancarrota. La imposibilidad de celebrar el referéndum polarizó aún más al pueblo, cada vez más fraccionado.

Entre 2007 y 2011 Obrisa negoció los acuerdos individuales para la construcción de los parques. Durante este período, el conflicto penetró en lo más profundo del tejido social local. Así, por ejemplo, pude documentar varios casos de riñas entre padres e hijos causadas por su desacuerdo sobre qué hacer con los contratos que la empresa eólica les ofrecía. Pero los conflictos más graves se dieron entre distintos grupos domésticos y/o familiares. La estrategia y las prisas de Obrisa fomentaron esos conflictos, puesto que la empresa empezó a negociar los arrendamientos anuales cuando los procesos de expropiación de Terraca aún estaban dirimiéndose. De esta manera, Obrisa promovió el enfrentamiento entre dos tipos de propietarios, creando una brecha entre aquellos "afortunados" a quienes había "tocado" (esta es la expresión usada localmente) un generador - cobrando por ello una renta anual - y los "desafortunados" a quienes les había "tocado" albergar la infraestructura asociada (zanjas, cableado, apertura de caminos, etc.) - cobrando por ello un único pago, por lo general bajo, en concepto de derecho de paso, y eso a pesar de que como suelen decir en La Fatarella, en clara referencia al hecho de que, si bien las parcelas agrícolas son privadas, el paisaje es colectivo: "Los molinos los vemos todos". Eva, una de las ingenieras que trabajaba para Obrisa, con una larga experiencia en el sector eólico, lo explica así: "Un molino es un alquiler por treinta años. Por [lo otro] pagas una vez lo que sea, pero es terreno rústico, es una mierda de terreno. Nunca son cantidades grandes". Los desafortunados, pues, tenían que elegir entre aceptar un trato de poca monta o ser expropiados, y muchos optaron por la segunda vía: en el parque situado dentro del término de La Fatarella, el último que se terminó, hasta 32 de 
los 110 propietarios afectados fueron expropiados. Esto no afectó a los "afortunados". Entre estos, incluso aquellos que no querían un generador en su propiedad sabían que la resistencia era fútil puesto que, como la empresa se encargaba de recordarles, siempre había la posibilidad de mover el generador a una parcela vecina, ya que siempre habría alguien que lo quisiera.

De hecho, Eudald y sus ingenieros eran incapaces de comprender cómo podía ser que algunos "afortunados" tuvieran tentaciones de rechazar los contratos, ya que entendían el generador como un "favor" o un "regalo". Y para hacer el trato aún más atractivo, Obrisa les ofrecía pagos por adelantado. Como me dijo una vez Eugènia: "El que tiene un molino debería estar agradecido, porque aquello no lo obtendrá de la finca en su vida". Así, gran parte de los afortunados (y por extensión, sus redes de parentesco) pasó a entender la resistencia de sus convecinos como una amenaza a sus ingresos, dando así pie a todo tipo de marrullerías, como reconoce Eva: "Una de las familias que tenía un molino regentaba un bar, y ya sabes que en un bar se oye de todo. Y nos llamaban para contarnos sobre aquellos que se quejaban más, y ve con cuidado con esos que arman jaleo...."

En definitiva, los parques eólicos alimentaron un clima de conflicto y desconfianza que intensificó el faccionalismo, avivando viejas enemistades y abriendo nuevas rencillas. Para describir este clima, los habitantes del pueblo usan una expresión peculiar: "Lo hicieron monte" (ho van fer garriga). Por los motivos indicados anteriormente, esta expresión identifica todo aquello que ha perdido dirección y cohesión: un campo yermo o abandonado, una casa que pierde nombre y propiedad o, como en este caso, un pueblo consumido por las rencillas internas. El paisaje natural y social del pueblo había escapado del control de sus habitantes, apareciendo ante ellos como un espacio desordenado.

El desarrollo eólico tuvo lugar en un contexto duro, marcado por la crisis y las mal llamadas políticas de austeridad, que se añadían a décadas de empobrecimiento y éxodo poblacional (Franquesa, 2019b). Muchos habitantes de la Terra Alta vieron este desarrollo como la puntilla en una larga agonía, tal y como me expresó un electricista de Corbera: "La Terra Alta era un cementerio, pero ahora le han puesto las cruces". En efecto, el desarrollo eólico contribuyó no sólo a desorganizar el tejido social, sino también a erosionar el sentimiento de autoestima entre la población local, dejando a muchos con la duda de que quizás la empresa tenía razón: quizás sus tierras, y con ellas ellos mismos, valían menos que los arrendamientos anuales; quizás eran un baldío.

\section{DIGNIDAD Y BALDÍO}

La erosión del sentimiento de autoestima es inseparable de la necesidad del promotor de superar las resistencias que se le oponían. Ello queda claro en las alegaciones que varios de los propietarios expropiados presentaron ante el juez y que quedan recogidas en las actas de expropiación. La siguiente cita, extraída de las alegaciones presentadas en 2010 
por Ferran, un carpintero y mediano propietario agrícola de La Fatarella, da cuenta del tono de estos documentos:

"Hay que valorar la zona afectada no solamente como metros cuadrados, sino como una tierra que se ha ido construyendo y modelando a lo largo de los años por muchas generaciones, y no tiene precio su valía inmaterial y moral. (...) Nos han humillado diciendo que nos hacían un favor pagando por unos terrenos que no valen nada. Olvidando que nuestra tierra no son solo metros cuadrados. Olvidando que es una tierra hecha a golpe de sangre. (...) Hay que respetar la dignidad de las personas".

Esta cita deja a las claras que la resistencia contra el desarrollo eólico no es sino una lucha contra la devaluación económica y la desvalorización moral. Para desmenuzar esta idea me centraré en dos de los aspectos sugeridos en la misma: la demanda de dignidad y las concepciones divergentes de lo que constituye un baldío.

La demanda de dignidad de Ferran hace referencia a la sensación de humillación producida por las negociaciones, y muy en particular por las expropiaciones. Pero debe situarse en un contexto histórico y social más amplio. Desde los años setenta, los catalanes del sur se han opuesto a los intentos por periferalizar la región y a cada nuevo proyecto energético con una demanda de dignidad en la que podemos apreciar dos momentos distintos (Franquesa, 2016). El primero es la indignación, la reacción fogosa del que se niega a aceptar pasivamente cualquier intento por rebajar su dignidad. Es lo contrario de la resignación y la deferencia, constituyendo así un primer momento en la defensa de la propia autoestima. El segundo momento se articula como una afirmación de la dignidad, entendida como valía: afirma el valor de la Cataluña Sur, de sus habitantes y de sus posesiones, tal y como hace Ferran al subrayar el valor acumulado de la tierra. Ello pone de manifiesto que la demanda de dignidad está íntimamente conectada con la lucha diaria para tirar adelante, ya que es un intento para preservar la reproducción de los modos de vida locales y para activar y proyectar hacia el futuro las condiciones que hacen posible que las gentes se ganen la vida. La demanda de dignidad debe pues ser vista como el elemento central de un marco teórico local orientado a explicar y combatir aquellas relaciones de valor que sustentan una estructura político-económica que convierte a los habitantes de la región (sus posesiones, su sentimiento de pertenencia, sus prácticas económicas) en baldíos, es decir, en aquello que la ley capitalista del valor tiene que devaluar, abaratar, para extraer valor de cambio.

Comprenderemos mejor esta idea si contrastamos la manera como compañías eólicas y población local definen lo que es un baldío. Si como he mostrado las primeras consideran que aquello que convierte a la tierra en baldío es precisamente su conexión con las prácticas de sus habitantes, localmente esta lógica se invierte: sólo aquella tierra que se ha dejado de cultivar, abandonada, es concebida como un baldío. Sin cuidado, su orden desaparece, las malas hierbas la conquistan y deviene yerma. En cambio, la tierra cultivada siempre es vista como productora y reproductora de vidas. 
No cabe duda de que la situación económica de la agricultura local es complicada, pero debemos ir con cuidado de no exagerar, pues la tierra sigue siendo un elemento crucial a la hora de estructurar estrategias reproductivas. Incluso cuando funciona como mero ingreso complementario, la tierra agrícola ofrece cierto margen de autonomía además de jugar un papel clave en la redistribución local de la riqueza en la Cataluña Sur. En cada pueblo hay un cierto número de gentes y familias que no trabajan su tierra: personas retiradas o discapacitadas, familias con buenos sueldos que no tienen tiempo ni quizás ganas de cosechar ellas mismas, etc. En su mayoría, estas personas contratan otros habitantes de su pueblo para hacer dicho trabajo, una decisión que a menudo se justifica con sanciones morales del estilo "Lo hago por respeto a mis mayores, para que no se revuelvan en la tumba". Así, mientras aquellos que descuidan su tierra son objeto recurrente de crítica en los bares, los que la tienen en buen estado - "peinada" es la expresión local - son alabados. La tierra también sirve para articular intercambios de dones (vino, aceite, avellanas, cerezas) con familiares, compañeros de trabajo y antiguos habitantes que vienen de visita, sirviendo así para mantener vínculos de gran importancia emocional y económica con la población urbanizada.

La demanda de dignidad del payés de la Cataluña Sur es parte de una lucha para establecer un cierto orden conducente a la reproducción de la sociedad local frente a una serie de fuerzas que introducen desorden, que abaratan la región y la construyen como un baldío. La tierra cultivada siempre es productiva y valiosa, ya que contribuye a la reproducción social. Pero para que esto suceda es necesario que la tierra sea "conservada", es decir, mantenida en producción a fin de que su valor se preserve, sus beneficios fluyan y sus posibilidades futuras sean retenidas. La tierra que no se cultiva, por el contrario, escapa de tales ciclos reproductivos.

Pero - y esto es clave - conservar la tierra implica conservar también lo que Gavin Smith (2016) llama "subjetividad resistente", debiéndose entender los llamados a la dignidad como íntimamente conectados a los esfuerzos por reproducir esta subjetividad. Para la mayor parte de habitantes de La Fatarella, tener cuidado de la tierra - e incluso permanecer en ella - es tanto una forma de obtener ingresos como una forma de resistencia. El modo de vida local se constituye a través de esta resistencia y es subjetivamente comprendido como tal. Reproducir la sociedad local (sus unidades domésticas, sus miembros, sus relaciones), conservar la tierra y mantener esta subjetividad son tres patas de un mismo modo de vida. La alternativa sólo podría ser la resignación, la obediencia. Indignarse significa no aceptar que la compañía eléctrica es dueña, no depender de ella, no participar de su orden moral.

\section{SOBRE EL VALOR, EL ABARATAMIENTO Y LA VALÍA}

Unos pocos años después de que Obrisa vendiera los parques, Eva entró a trabajar en la división de energías renovables de una multinacional eléctrica española. Ya en su nuevo 
cargo, le pregunté qué opinaba de la venta. Me dijo que el precio había sido muy elevado y que podía parecer sorprendente, pero que había que tener en cuenta que a la empresa compradora sólo le quedaba por hacer la parte fácil del proceso: "Construir es un accidente. Lo importante es toda la promoción, todo el trabajo este [previo]. Y después, construir es un añito y después la explotación”. Eva me explicó que la parte difícil del desarrollo eólico es conseguir acceso a licencias y sobre todo a tierras, y que ello es así porque cada proyecto de parque tiene que sobreponerse a todo tipo de resistencias y oposición locales.

Eva caracteriza la oposición local que ella ayudó a derrotar como derivada, por un lado, de la acción y la propaganda, a su juicio engañosa, de las plataformas y, por el otro, de una población rural sobre la que proyectó estereotipos recurrentes: es ignorante - y por lo tanto fácil de manipular por parte de las plataformas - además de pobre y cerrada - y por lo tanto con tendencia a sentir envidia de aquellos a quienes sonríe la fortuna, especialmente si son sus convecinos. Pero esta argumentación tiene los pies de barro ya que, como Eudald razonaba en la introducción, las comarcas rurales más ricas y mejor conectadas ofrecen una resistencia aún mayor a los proyectos eólicos porque, como me dijo Eva, sus habitantes "tienen dinero y ... pueden permitirse el lujo de despreciarte".

Este artículo se ha esforzado por descifrar la compleja relación dialéctica que el desarrollo eólico mantiene con los procesos de devaluación en aquellos lugares donde este desarrollo ha tomado un carácter extractivista. Como Eva nos acaba de decir, en el Estado español el negocio eólico prospera en zonas rurales, periféricas y empobrecidas que sólo pueden ofrecer una resistencia débil. Allí es fácil convencer a la población de que, en vez de negociar por su participación en el negocio eólico que se desarrolla en sus pueblos y tierras, debería comprender los generadores como un favor que se les concede o que les ha tocado. Pero los promotores no se limitan a encontrar estas áreas de poco valor, sino que necesitan construirlas material y discursivamente como tales. Lo hemos visto a lo largo del artículo: con el estudio de impacto económico, con los procesos de expropiación, con las artimañas negociadoras de la compañía. Tal proceso de abaratamiento justifica la intervención de los promotores a la vez que erosiona el control de la población local sobre su entorno físico y social y, en última instancia, sobre sus propias mentes, su propia autoestima y su propia valía. Pero, de forma dialéctica, la necesidad del promotor de construir la zona como un baldío alimenta nuevas formas de resistencia. Como hemos visto en el caso de La Fatarella, la oposición al desarrollo eólico emerge de la necesidad percibida de defender el respeto hacia uno mismo y sus convecinos, de controlar el propio entorno, de afirmar el valor del paisaje agrícola, íntimamente conectado a formas de subjetividad resistente que son esenciales para la reproducción social. 


\section{BIBLIOGRAFÍA}

Argenti, Nicolás y Daniel Knight (2015) "Sun, wind, and the rebirth of extractive economies: Renewable energy investment and metanarratives of crisis in Greece”. Journal of the Royal Anthropological Institute 21(4), pp. 781-802.

Ariza-Montobbio, Pere (2013) Large-scale renewable energy? A transdisciplinary view on conflicts and trade-offs in the implementation of renewable energy. Tesis doctoral, Universitat Autònoma de Barcelona.

Ávila-Calero Sofia (2017) "Contesting energy transitions: Wind power and conflicts in the Isthmus of Tehuantepec". Journal of Political Ecology 24, pp. 992-1012.

Barcia Magaz, JV y Cote Romero (eds.) (2014) Alta tensión. Por un nuevo modelo energético sostenible, democrático y ciudadano. Barcelona: Icaria.

Boyer, Dominic y Cymene Howe (2019) Wind and power in the Anthropocene. Durham: Duke University Press.

Carpintero, Óscar (dir) (2015) El metabolismo económico regional español. Madrid: FUHEM Ecosocial.

Dunlap, Alexander (2019) Renewing destruction: Wind energy development, conflict and resistance in a Latin American context. Londres: Rowman \& Littlefield.

Escobar, Arturo (2005) "Una ecología de la diferencia: igualdad y conflicto en un mundo glocalizado”. En Más allá del Tercer Mundo. Globalización y diferencia. Bogotá: Instituto Colombiano de Antropología e Historia, pp. 123-144.

Fernández, Joaquín (1999) El ecologismo español. Madrid: Alianza.

Franquesa, Jaume (2016) "Dignity and indignation: Bridging morality and political economy in contemporary Spain”. Dialectical Anthropology 40(2), pp. 69-86.

(2018) Power struggles: Dignity, value, and the renewable energy frontier in Spain. Bloomington: Indiana University Press.

(2019a) "Resources: Nature, value and time”. En James Carrier (ed.) A research agenda for economic anthropology. Cheltenham: Edward Elgar, pp. 74-89.

(2019b) “The vanishing exception: Republican and reactionary specters of populism in rural Spain”. Journal of Peasant Studies 46(3), pp. 537-560.

Garcia, Xavier (1997) Catalunya tambe té sud. Barcelona: Flor del Vent.

Gidwani, Vinay (1992) “'Waste' and the permanent settlement in Bengal”. Economic and Political Weekly 27(4), pp. 39-46. 
(2012) "Waste/Value". En Trevor Barnes et al. (eds.) The Wiley-Blackwell companion to economic geography. Maldon: Wiley-Blacwell, pp. 275-288.

Hvelplund, Frede (2014) "Black or green wind power". En Preben Maegaard et al. (eds) Wind power for the world: International reviews and developments. Singapur: Pan Stanford Publishing, pp. 79-90.

Márquez Porras, Raúl (2019) "La fiebre de las algas. Forma y dinámicas del extractivismo en la costa chilena”. Revista Andaluza de Antropología 17, pp. 52-71.

Moore, Jason (2017) “The Capitalocene, Part I: On the nature and origins of our ecological crisis". Journal of Peasant Studies 44(3), pp. 594-630.

Nadaï, Alain y Dan van der Horst (2010) "Wind Power Planning, Landscapes and Publics". Land Use Policy 27(2), pp. 181-184.

Oceransky, Sergio (2010) "Fighting the enclosure of wind: Indigenous resistance to the privatization of the wind resource in Southern Mexico". En Kolya Abramsky (ed.) Sparking a worldwide energy revolution. Londres: AK Press, pp 505-522.

Saladié, Sergi (2018) Conflicte entre el paisatge i l'energia eòlica: El cas de les comarques meridionals de Catalunya. Lleida: Pagès.

Scott, James (1985) Weapons of the week: Everyday forms of peasant resistance. New Haven: Yale University Press.

Siamanta, Zoi y Alexander Dunlap (2019) “'Accumulation by wind energy': Wind energy development as a capitalist trojan horse in Crete, Greece and Oaxaca, Mexico". ACME 18(4), pp. 925-955.

Smith, Gavin (2016) "Against social democratic angst about revolution". Dialectical Anthropology 40 (3), pp. 221-239.

Szarka, Joseph (2007) Wind power in Europe: Politics, business and society. Basingstoke: Palgrave Macmillan.

Tomàs, Manel (2002) "Prefaci”. En Josep Pont (dir) La lluita per l'Ebre: El moviment social contra el Pla hidrologic nacional. Barcelona: Mediterrània, pp. 7-10.

Tsing, Anna (2015) The mushroom at the end of the world: On the possibility of life in capitalist ruins. Princeton: Princeton University Press.

Zografos, Christos y Joan Martínez-Alier (2009) “The politics of landscape value: A case study of wind farm conflict in rural Catalonia". Environment and Planning A 41, 1726-44. 